\title{
FORMAÇÃO CONTINUADA: UM INSTRUMENTO DE TRANSFORMAÇÃO NA EDUCAÇÃO A PARTIR DA CORRELAÇÃO TEÓRICO-PRÁTICO NO CONTEXTO ESCOLAR
}

\section{ARTIGO ORIGINAL}

FERREIRA, Maria Edite ${ }^{1}$, MENDES, Celeste ${ }^{2}$

FERREIRA, Maria Edite. MENDES, Celeste. Formação continuada: um instrumento de transformação na educação a partir da correlação teóricoprático no contexto escolar. Revista Científica Multidisciplinar Núcleo do Conhecimento. Ano. 06, Ed. 12, Vol. 05, pp. 32-49. Dezembro de 2021. ISSN: 24480959, Link de acesso: https://www.nucleodoconhecimento.com.br/educacao/transformacao-naeducacao

\section{RESUMO}

A formação continuada de professores tem sido objeto de muitos estudos e exige análises permanentes sobre sua configuração. Considerando as inúmeras mudanças nos sistemas social, cultural, político e econômico, essa imposição apresenta-se tanto como condição para acompanhar a evolução do conhecimento, como para redirecionar as ações docentes em busca do atendimento às novas demandas

\footnotetext{
${ }^{1}$ Mestre em Ciências de Educação pela Universidade Interamericana do Paraguai; graduada em Pedagogia pela Faculdade de Ciências e Letras de Jales. ORCID: https://orcid.org/0000-0002-2948-0701

2 Doutora em Ciências da Educação pela Universidad Tecnológica Intercontinental; Mestre em Ciências da Educação pela Universidad Tecnológica Intercontinental; Especialista em Psicopedagogia e Gestão Escolar ambas realizadas através da Universidade Federal de RO - UNIR; Graduada em Pedagogia / Administração Escolar pela Faculdade de Filosofia, Ciências e Letras de Jandaia do Sul. ORCID: https://orcid.org/0000-0001-6070-3777
} 
educacionais. Discute-se ainda a combinação de alguns fatores, que, juntos, poderiam corroborar para que esta formação seja significativa ao professor e eficaz para o processo de aprendizagem e de desenvolvimento profissional daqueles que a ela se submetem. Neste contexto, o presente artigo, tem como questão norteadora: Qual a importância da formação continuada para os professores? O objetivo deste trabalho é discutir a formação continuada, proposta para os professores da Rede Estadual de Educação, analisar os encontros e discutir a interação colaborativa desta proposta de acordo com a literatura já publicada. Para tanto, tem-se como metodologia uma revisão bibliográfica a partir do método materialista-dialético. Os resultados e discussões apontam que a formação continuada será significativa ao professor quando houver maior articulação entre teoria e prática. Além disso, percebeu- se que a formação continuada é capaz de provocar mudanças na postura e no fazer pedagógico dos professores por meio de programas de formação continuada, que tem como objetivo formar profissionais competentes, dotados de uma fundamentação teórica consistente e com capacidade de análise e reflexão crítica acerca de todos os aspectos que compõem e influenciam o contexto escolar.

Palavras-chave: Educação, Docência, Formação Continuada, Formação de Professores.

\section{INTRODUÇÃO}

Ao longo das últimas décadas, com o advento da globalização da economia, da reestruturação produtiva e do neoliberalismo, mudanças significativas ocorreram com o impacto do ajuste da nova ordem do processo escolar e das políticas educacionais vigentes. Tais transformações intervêm nas esferas da vida social, política e educacional, instaurando uma efetiva democratização do ensino.

Para fazer um contraponto a estas mudanças, é hora de repensar o papel dos profissionais da educação, bem como seu compromisso político e competência técnica. É evidente que esses profissionais necessitam de um espaço para a sua formação, a partir de um novo formato que possa estabelecer diferentes maneiras de organizar o trabalho na escola e potencializar discussões que atendam aos objetivos 
de contribuir efetivamente com a prática educativa nos meios do direito social que se adquire ao se qualificar.

Neste contexto, o presente artigo, tem como questão norteadora: Qual a importância da formação continuada para os professores? O objetivo deste trabalho é discutir a formação continuada, proposta para os professores da Rede Estadual de Educação, analisar os encontros e discutir a interação colaborativa desta proposta a partir do método materialista-dialético, utilizando como metodologia a pesquisa bibliográfica.

Assim, a formação dos professores deve ser orientada por uma teoria. É necessário que a teoria seja ressaltada sem desconsiderar a importância da prática, não só para uma reflexão sobre novas possibilidades de acesso ao conhecimento, como para uma análise da própria prática. Sem uma formação teórica sólida fica difícil, por exemplo, fazer uma análise histórica sobre a profissão docente, a escola e o conteúdo a ser ensinado no contexto social atual.

\section{ASPECTOS PRELIMINARES}

Concebe-se a formação continuada em serviço tendo a escola como espaço de formação, porque, desta forma, se articula melhor as condições de trabalho e carga horária dos professores. É no "chão" da escola que propostas de mudanças devem ser levantadas, discutidas e concretizadas no projeto político pedagógico, garantindo um processo formativo que promova a tomada de consciência para a construção da escola democrática.

Por muito tempo, a formação inicial foi considerada essencial e suficiente para a preparação do indivíduo para o mercado de trabalho e para seguir em frente com projeção profissional considerável, porém, o mundo sofre constantes transformações, e o que era uma verdade há pouco tempo, hoje já é deixada de lado e substituída por outras situações apropriadas ao desenvolvimento, e isso gera impacto em toda a vida profissional, na sociedade e na família.

Entretanto, o avanço do conhecimento nem sempre é seguido com tanta destreza e habilidade pela educação. Ao passo que novas exigências surgem, a escola precisa 
se reorganizar para compreender esse inter-relacionamento e repensar seus atos através do desempenho profissional adequado. Dessa forma, vem à tona a necessidade de atualização e de aperfeiçoamento constante dos que atuam na educação. Rodrigues e Esteves (1993, p. 41) asseveram que:

A formação não se esgota na formação inicial, devendo prosseguir ao longo da carreira, de forma coerente e integrada, respondendo às necessidades de formação sentidas pelo próprio professor e às do sistema educativo, resultantes das mudanças sociais e/ou do próprio sistema de ensino.

Dessa maneira, se torna fundamental o estabelecimento de uma formação inicial que proporcione ao futuro professor um conhecimento válido e gere uma atitude interativa e dialética que o incentive a valorizar a necessidade de atualização permanente em função das mudanças que se produzem.

De acordo com Nóvoa (1995), pode-se afirmar que a formação inicial mantém características constituídas na sua gênese, não sendo mais entendida como um local que encerra a aquisição da competência necessária "ao ser professor" (NÓVOA, 1995).

Surge, então, a necessidade de formação continuada de quem já é professor, a partir da prioridade da evolução do conhecimento em relação aos processos de ensinar, de aprender e da difusão do saber socialmente constituído, quanto ao fracasso escolar expresso nos índices de repetência e evasão dos alunos, e das reformas empreendidas no sistema e nos currículos.

Dessa maneira, a educação no Brasil, há mais de um século, procura adequar-se às suas diversidades e particularidades, uma vez que, por sua grande extensão, possui diferentes necessidades, tanto no crescimento educacional como de abertura de novas possibilidades de desenvolvimento e de formação com o propósito de adequarse às peculiaridades de cada espaço geográfico a evolução existente.

É nesse sentido que se torna relevante indagar como essa formação continuada está acontecendo e qual a importância que ela vem assumindo para os professores e para os alunos. É preciso, também, levar em consideração o tempo e o período destinado 
à formação e o enfoque que vem sendo dado às necessidades elencadas como prioridade diante de uma sociedade em que as transformações ocorrem o tempo todo.

\section{CONCEITUAÇÃO DE FORMAÇÃO CONTINUADA}

De acordo com o dicionário Michaelis (2001), o vocábulo "formação" deriva do latim formationee e tem o sentido de formar, construir, que por sua vez está em processo de interação e de transformação de conhecimentos. É um fazer permanente que se refaz constantemente na ação. A formação não ocorre por mera acumulação de conhecimentos, mas constitui uma conquista tecida com ajuda: de livros, de mestres, de aulas, de conversas entre professores, da internet, dentre outros.

Para tanto, depende-se sempre de um trabalho de teor pessoal. Portanto, ninguém forma ninguém, cada um forma-se a si mesmo. Na formação se pode adotar diferentes aspectos, de acordo com o sentido que se atribui ao objeto da formação, ou a concepção que se tem do sujeito. Garcia (1999, p. 30) descreve que:

(...) os princípios não esgotam a multiplicidade de abordagens que a formação de professores contém enquanto disciplina", mas "contribuem para uma primeira definição da nossa concepção da formação de professores e dos métodos mais apropriados para o seu desenvolvimento.

Na concepção de Freire (1997, p. 25), a formação pode ser vista da seguinte forma:

Quem ensina, aprende ao ensinar, e quem aprende, ensina ao aprender. Não há ensino sem pesquisa e pesquisa sem ensino. Enquanto ensino, continuo buscando, reprocurando. Ensino porque busco, porque indaguei, porque indago e me indago. Pesquiso para constatar, constatando, intervenho, intervindo educo e me educo. Pesquiso para conhecer o que ainda não conheço e comunicar ou anunciar a novidade.

Nessa perspectiva, são ações de formação continuada: congressos, seminários, simpósios, colóquios, encontros, jornadas, ciclos de falas, palestras, grupos de pesquisa, grupos de estudos, grupos de formação, projetos de pesquisa, oficinas, cursos de extensão e/ou aperfeiçoamento sobre um conteúdo específico e/ou questões pedagógicas efetuados no lócus da escola, nas instituições de ensino superior e em outros espaços. 
Além dessas ações pontuais, são considerados os cursos de pós-graduação lato sensu, pós-graduação stricto sensu (mestrado e doutorado) e processos permanentes realizados no lócus da escola ou não, com encontros regulares. Cada proposta, de acordo com suas características, propicia o atendimento a diferentes necessidades e interesses dos professores, podendo contribuir como suporte ao docente e ao desenvolvimento profissional.

Dessa maneira, a formação pode ser compreendida a partir de três aspectos: como função social de transmissão de saberes, de saber fazer ou de saber ser, que se referem, respectivamente, aos conceitos, aos procedimentos e às atitudes. Esta classificação corresponde às perguntas: O que se deve saber? O que se deve saber fazer? E como se deve ser? Com o desígnio de alcançar as capacidades propostas nas finalidades educacionais do sistema socioeconômico ou da cultura dominante.

O termo, porém, já sofreu várias alterações com o passar do tempo. Nas décadas dos anos 60 aos 80, no auge da guerra fria, as ações desenvolvidas, nesse sentido, levavam o nome de "capacitação, reciclagem e treinamento". Entre outras atitudes, pretendia-se melhorar a qualidade da educação, a alfabetização e o acesso aos produtos industriais e tecnológicos, além da formação de mão de obra qualificada. Em tempos atuais, o termo formação continuado é percebido como um processo de desenvolvimento e de estruturação da pessoa que se realiza em decorrência da maturação interna e das possíveis experiências dos sujeitos.

Diante do que foi exposto, é possível compreender que o conceito de formação é suscetível a múltiplas perspectivas, mas tem sido recorrente associar o conceito ao seu desenvolvimento pessoal e profissional. Assim, se verifica novas abordagens a respeito da formação de professores, saindo de uma perspectiva centrada na dimensão acadêmica para uma perspectiva no terreno profissional, pessoal e de organização, a partir do contexto escolar, na jornada de formação e desenvolvimento que o ser humano percorre até atingir um estado de plenitude pessoal.

Inclui-se problemas relativos aos fins ou modelos a alcançar, os conteúdos e experiências a assumir, alia-se às interações sujeito e meio, aos estímulos e planos 
de apoio no processo. Mantém-se relação com o ideológico cultural, como espaço que define o sentido geral dessa formação como processo.

Pode-se dizer que a formação continuada é, antes de tudo, uma releitura das experiências que ocorrem na vida profissional, significando uma atenção prioritária às práticas, no caso da educação e dos professores. Também se pode ressaltar que o espaço de formação continuada não está restrito a um determinado tempo e espaço, mas que se situa em todas as suas dimensões coletivas, profissionais e organizacionais, concebendo essa formação como uma intervenção educativa solidária aos desafios de mudanças das escolas e dos professores (NÓVOA, 1997).

Portanto, o aprender contínuo é essencial na profissão do educador, pois o professor deve se basear em sua pessoa enquanto sujeito e na escola enquanto lugar de crescimento profissional permanente.

Dessa forma, podemos afirmar que estamos passando de uma lógica que separa os diferentes tempos de formação, em que se considera apenas o seu princípio, para outra que percebe esse desenvolvimento profissional como um processo ao longo da vida do educador.

\section{A FORMAÇÃO CONTINUADA FRENTE ÀS TENDÊNCIAS PEDAGÓGICAS}

A formação de professores já enfrentou distintas barreiras e sofreu grandes transformações no desenrolar dos fatos sociais e de desenvolvimento cultural. Com muitas mudanças a serem encaradas, ainda se percebe a preocupação de fomentar no profissional a necessidade de sempre estar construindo sua aprendizagem a partir do contexto vivenciado e oferecido pelas inovações. Desse modo, tem se a percepção de que a formação continuada da educação brasileira foi compreendida a partir de diversas tendências que marcaram o cenário educacional, as quais corresponderam a diferentes concepções pedagógicas. 
Fiorentini (2000) observou que, nos últimos anos, as pesquisas sobre a formação de professores apresentaram os seguintes pressupostos: a partir de 1960 houve uma maior valorização do conhecimento específico a ser ensinado; a partir de 1970 houve uma maior ênfase nos aspectos didáticos e pedagógicos e nas tecnologias de ensino; a partir de 1980 houve um maior destaque para as dimensões sócio-política e ideológica e em 1990 deu-se início ao enfoque sobre a prática docente e os saberes pedagógicos.

Nota-se, sobretudo, alguns pontos marcantes na forma como a educação vem sendo compreendida, principalmente a partir de meados do século XX, quando a tendência escolanovista influencia a tentativa de fazer um contraponto à escola tradicional, que era rígida e estática, propondo que houvesse espaço às demandas da função social e se voltando à produção capitalista e a pedagogia do "aprender a aprender", uma nova configuração em que a escola assume um caráter pragmático, tornando-se hegemônica e dando espaço às demandas da sociedade.

Nessa ótica educacional, o aluno passa a ser autônomo em relação a aprendizagem, de modo que busca o que lhe é de interesse e se apropria de sua própria experiência, sendo capaz de abstrair conceitos e relações que Ihe são significativas. $O$ aluno aprende sozinho e, com isso, conquista sua autonomia. O professor fica desobrigado de "ensinar" e se torna apenas um facilitador e mediador da aprendizagem com uma formação fundamentada em sua experiência profissional cotidiana.

Também é a partir da escola nova que surgem as ideias como a pedagogia dos projetos e a metodologia ativa, em que as atividades devem se organizar em torno de projetos, não de currículos; a pedagogia das competências, cujo objetivo é desenvolver competências para mobilizar conhecimentos na experiência cotidiana, resolvendo problemas propostos pela prática, e a pedagogia multiculturalista, evidenciando o relativismo cultural.

Já no final dos anos 70, outra ótica permeia o fazer pedagógico: a influência marxista traz à tona questões relacionadas ao papel da escola como reprodutora da classe 
dominante, questionando a sua função e a marca que impera em detrimento dos mais favorecidos, sendo insuficiente, principalmente, para os que mais precisam da escola.

Estudos e debates seguem contrapondo essa teoria e buscando dos professores um compromisso maior com o saber sem distinção. Nesta perspectiva, Saviani (2000) propõe a formação de professores orientada por uma reflexão sistemática, na qual o papel da escola é socializar os conteúdos historicamente produzidos pela humanidade, preparando o aluno para a participação ativa na democratização da sociedade. O professor é a autoridade competente que deve direcionar o processo de ensino e aprendizagem.

As discussões giram em torno da análise crítica do modelo reprodutivista imposto pelas classes dominantes. Assim, Saviani (2000) redefine o papel da escola e da educação em: combater a ideologia dominante rumo à transformação social. Nesse sentido, é urgente um olhar crítico e reflexivo sobre as políticas educacionais, incluindo as de formação docente, existentes em uma sociedade tão desigual. Depois de muitos debates e de estudos baseados, principalmente, em autores que mundialmente se tornaram destaque, como Paulo Freire, a educação se torna alvo de muitos estudos e correntes que se preocupam que esta abarque todos os que precisam nela estar. Porém, ainda há um abismo muito grande entre o ideal e o real.

Chega então em cena a era tecnicista, em que os anos 80 marcam a educação com a necessidade de implantar um modelo voltado aos princípios de racionalidade, eficiência e produtividade, o qual visa formar mão de obra especializada para 0 mercado de trabalho e que ganha olhares no sistema escolar brasileiro. Assim, a demanda social busca na escola, parceria para formar o "técnico". O foco educacional passa a ser a organização racional dos meios. O professor é um técnico e, desta forma, são compensadas e corrigidas suas deficiências.

Nesse longo caminho entre a formação inicial e os modelos que ora a educação assume, depende-se particularmente de quem gera as esferas autárquicas da educação brasileira. Nos anos 90 , a ordem prioritária dos governantes passa a ser a inserção do país no mercado globalizado, de forma que as políticas sociais buscam 
se manter atreladas ao bom desempenho da economia, cabendo à educação, de forma subordinada, o que sobra, e não o que atenderia às necessidades efetivas da população. (SAVIANI, 2000)

Em se tratando de produção de pesquisa na área de formação continuada, André (2005) destaca que a década de 1990 teve como foco as propostas oficiais realizadas na instituição escolar e concebidas em serviço, enfatizando o papel do professor como profissional e a prática pedagógica. De acordo com a autora, os artigos periódicos evidenciam a necessidade da articulação entre teoria e prática, destacando um tratamento isolado das disciplinas específicas e pedagógicas, dos cursos de formação e da práxis e da formação inicial e continuada. (ANDRÉ, 2005)

Foi a partir de então que se passou a levantar hipóteses entre os professores a respeito de que tipo de aluno a sociedade e a escola pretendiam formar, bem como que tipo de formação orientaria as próximas ações. Dessa forma, pôde-se notar que, na atualidade, a fomentação entre a formação inicial e as atividades propostas para a formação continuada procuram contornar a velha dicotomia entre teoria e prática. Muitos trabalhos se baseiam em autores como Schön (1992), Nóvoa (1991), dentre outros, os quais defendem a racionalidade prática e o professor reflexivo.

\section{A FUNÇÃO DA FORMAÇÃO CONTINUADA}

De acordo com os estudos de Donald Schön (1992) no campo da formação profissional em geral e da formação de professores em particular, fundamenta-se uma epistemologia que desvaloriza o conhecimento científico/teórico/acadêmico e uma pedagogia que desvaloriza o saber escolar. Assim, requer-se dos profissionais um perfil com capacidade de criar novas perspectivas e de atender os problemas de maneiras não previstas em seu conhecimento anterior.

A ordem atual está intimamente ligada a atividades de reflexão, nas quais o professor assume a postura de pesquisador da prática ou de "professor reflexivo". Notadamente, não se fundamenta em teorias e práticas preestabelecidas, construindo sua própria 
maneira de observar o problema, e por meio dessa atividade o currículo sempre se apresenta em processo de construção e transformação.

Embora a contribuição do professor deva ser considerada, a questão é que o conhecimento pode vir parcialmente da prática, mas não há como situá-lo exclusivamente nesta dimensão, valorizando o conhecimento tácito em detrimento do conhecimento escolar. O professor é, acima de tudo, um ser reflexivo, pois está se mostra a melhor forma de prepará-lo para situações desafiadoras e para as inovações do mundo globalizado.

Contudo, é preciso ter em mente que para atender as demandas atuais de formação, em uma sociedade excludente, com grande número de analfabetos e com escolas de baixa qualidade, não há como negar o valor dos conteúdos escolares, pois as escolas públicas são as que mais necessitam de professores que propiciem conhecimento para o enfrentamento destes desafios.

Nesse sentido, é preciso ressaltar o que diz Saviani (2000) sobre a função social da escola ser transmitir o conhecimento historicamente construído ao longo do tempo, para que o indivíduo perceba criticamente a realidade social e possa se comprometer com a sua transformação. Outros autores também mantêm a preocupação com a qualidade do que a escola oferece. Libâneo (2002, p. 53-79), referindo-se à valorização dos conhecimentos, menciona que:

Nenhuma política de capacitação será bem-sucedida se não se voltar para os conteúdos. Obviamente, se esperamos da educação escolar a relação do aluno com os conteúdos, é fundamental que o mediador dessa relação também tenha um domínio seguro deles, de sua ligação com a prática e com problemas concretos, que saiba trabalhar os conteúdos como instrumentos conceituais para leitura da realidade.

Para que o profissional do século XXI possa atender às necessidades educacionais do novo milênio e se reconhecer como um agente em transformação, é preciso que ele se aproprie de todas as possibilidades de aprendizagem possíveis.

Em um contexto tão vasto e com tantas possibilidades, o professor da atualidade deve manter o domínio do conhecimento e dos aportes teóricos que norteiam as 
concepções pedagógicas, de modo a compreender a importância fundamental da formação continuada, que o possibilita sustentar seu trabalho prático, proporcionando condições para que modifiquem suas concepções e ações. Libâneo (1998) ainda discute a importância do conhecimento nas políticas de formação:

\begin{abstract}
Argumentou-se neste texto que as políticas de capacitação precisam retomar o que é prioritário na formação: atender às funções sociais da escola e aos objetivos de formação propostos para os alunos. Ora, essas funções e esses objetivos relacionam-se diretamente com o conhecimento; conhecimento que se torna cultura, que ajuda a explicar e a compreender as realidades econômicas, sociais, culturais, políticas, visando a apropriação histórica dessas realidades e a intervenção nela. Definidas essas responsabilidades inerentes às escolas e ao trabalho dos professores, resta definir os meios de realização dos cursos, seminários.
\end{abstract}

Nesta perspectiva, pode-se afirmar que as atividades de formação que constituem esta proposta se orientam por dois objetivos: a ampliação do universo de conhecimento dos professores e a reflexão da concepção pedagógica histórico-crítica como orientadora da prática.

Desse modo, compreender o conhecimento como o aporte teórico possibilita que profissional tenha pleno conhecimento dos conteúdos específicos das disciplinas resultante da experiência acumulada da humanidade e sistematizada pela escola, além de possuir conhecimento histórico e social que envolve os diferentes conceitos e a aplicabilidade de toda essa teoria no contexto em que o aluno vive. Este saber sistematizado contribui para as transformações e avanços e valida a excelência do saber para os dias atuais.

Referindo-se ao saber docente, o conhecimento das concepções pedagógicas que sustentam a ação educativa também é de suma importância, pois são elas que, desenhadas de forma consistente, se articulam à prática. Nesse sentido, vale dizer, sem desmerecer a importância da prática, que é preciso ressaltar a teoria, não só para a reflexão sobre novas possibilidades de conhecimento, mas também como requisito para uma análise da própria prática. Sem formação teórica sólida não há compreensão histórica para entender a profissão, a escola e o conhecimento no contexto social vigente. 
Saviani (2001) relata que tais concepções se fundamentam a partir do método materialista dialético-histórico, na busca do enfrentamento dos desafios, e toma como princípio a tendência pedagógica histórico-crítica. $O$ autor ainda afirma que a formação continuada não deve se resumir à busca de resolução de problemas específicos de sala de aula, mas que deve fazer com que o professor ultrapasse a visão compartimentada da atividade escolar e passe a analisar os acontecimentos sociais, contribuindo para sua transformação.

Contreras (2000) alerta que é preciso fugir da incorporação de discursos e "modismos" que, no seu contexto, relegam o segundo plano, a democratização, o acesso e apropriação do conhecimento necessário para o desenvolvimento intelectual e humano dos nossos alunos, que está presente em determinados vieses de propostas de formação continuada. O professor deve ter em mente o compromisso de contribuir com o conhecimento de seus alunos, de modo a promover a transformação estrutural da sociedade. Segundo Saviani (1983, p. 83):

Tal contribuição (...) se consubstancia na instrumentalização, isto é, nas ferramentas de caráter histórico, matemático, científico, literário etc., que o professor seja capaz de colocar de posse dos alunos.

O professor deve partir da prática social como modo de buscar, qualitativamente, a prática de seus alunos, enquanto agentes de transformação social. O significado do trabalho do professor é formado pelo seu objetivo de ensinar, tendo como finalidade a apropriação do conhecimento pelo aluno, consciente das condições reais e objetivas do processo ensino-aprendizagem.

\section{A IMPORTÂNCIA DA FORMAÇÃO CONTINUADA NO CENÁRIO}

\section{ATUAL}

Como relatado no item anterior, a preocupação com a formação continuada de professores vem se mostrando há muito tempo, visto que o não o tema não é uma novidade e nem tampouco a sua significância. Muitos são os autores que apresentam discussões sobre esta temática e ressaltam a relevância desta para os profissionais do ensino, dentre os quais podemos citar: Nóvoa (1999), Nascimento (2000), Pimenta 
(2002), entre outros, que discorrem da sua importância, relacionando-a com a necessidade de mudança da escola.

Segundo Shigunov Neto e Maciel (2002), para que as mudanças que ocorrem na sociedade atual possam ser acompanhadas, é preciso um novo profissional do ensino, ou seja, um profissional que valorize a investigação como estratégia de ensino, que desenvolva a reflexão crítica da prática e que esteja sempre preocupado com a formação continuada.

A formação continuada, ao ser entendida como parte do processo de desenvolvimento profissional que acontece ao longo da atuação docente, possibilita um novo sentido à prática pedagógica, pois, ao contextualizar novas circunstâncias e ressignificar a atuação do professor, a torna reflexiva. Trazer novas questões da prática e buscar compreendê-las sob o enfoque da teoria e na própria prática permite articular novos saberes na construção da docência, dialogando com os envolvidos no processo que envolve a formação (IMBERNÓN, 2010).

Nesse sentido, a formação de professores é entendida como a prática que necessita de uma reflexão na ação, para que se pense sobre o que foi transformado. Consequentemente, valoriza-se o conhecimento prático do professor, colocando-o na condição de investigador das suas próprias atitudes, que realiza sua formação por meio do processo de investigação.

Assim, pode-se dizer que a formação continuada está diretamente ligada ao papel do professor, às possibilidades de transformação de suas práticas pedagógicas e às possíveis mudanças do contexto escolar. Imbernón (2010) ainda ressalta a formação continuada como fomento de desenvolvimento pessoal, profissional e institucional dos professores, elevando seu trabalho para transformação de uma prática.

Tal prática consiste em rever todo o processo profissional, indo além das atualizações científicas, didáticas ou pedagógicas do trabalho docente. Supõe-se uma prática cujo alicerce é balizado na teoria e na reflexão desta, para mudança e transformação no contexto escolar, assim: 
O conhecimento profissional consolidado mediante a formação permanente apoia-se tanto na aquisição de conhecimentos teóricos e de competências de processamento da informação, análise e reflexão crítica em, sobre e durante a ação, o diagnóstico, a decisão racional, a avaliação de processos e a reformulação de projetos (IMBERNÓN, 2010, p. 75).

Para Nóvoa (1999), é fundamental conhecer o professor, sua formação básica e como ele se constrói ao longo da sua carreira profissional. Esses são pontos fundamentais para que se compreendam as práticas pedagógicas dentro das escolas. Se tornar professor é um processo de longa duração, de novas aprendizagens e sem um fim determinado.

A formação continuada, é percebida, então, como uma possibilidade de mudança das práticas no âmbito dos docentes e da escola, permitindo a experimentação do novo e do diferente a partir das experiências profissionais que ocorrem neste espaço e tempo, orientando um processo constante de mudança e intervenção na realidade em que se insere e predomina esta formação.

Conforme Hargreaves (2002, p. 115), "Uma inovação bem-sucedida implica mais do que aperfeiçoar habilidades técnicas. Ela também estimula a capacidade de compreensão dos professores em relação às mudanças que estão enfrentando."

Desse modo, presume-se que um projeto de formação significativo busca contemplar os significados e as interpretações que os docentes atribuem à necessidade de mudança e o grau de importância desta em suas crenças e práticas.

Nesse sentido, pode-se levar em conta a última das quatro fases no "aprender a ensinar". A qual trata da formação permanente, que inclui todas as atividades planificadas pelas instituições, ou até mesmo pelos próprios professores, mediante as necessidades observadas, de modo a permitir o desenvolvimento profissional e aperfeiçoamento do seu ensino. Tal atitude pode, ainda, ser delimitada como um processo de constante aprendizagem, mediante o qual a comunidade profissional, formada por professores, gestores e equipe pedagógica, deve desenvolver conhecimentos, competências, disposições e atitudes em num contexto concreto, seja na escola, na universidade ou no centro de formação. 
O currículo, neste caso, refere-se à planificação, a forma de execução e avaliação de todo o processo formativo, evidenciando atitudes que tendem a melhorar a competência profissional dos professores. Portanto, a formação continuada, em seu entendimento formal, é um processo de ensino intencional, inserido em um curso que visa à melhoria da prática do professor em sala de aula. Segundo Garrido e Ghedin (2002, p. 26):

O papel da teoria é oferecer aos professores perspectivas de análise para compreenderem os contextos históricos, sociais, culturais, organizacionais e de si mesmos como profissão, nos quais se dá sua atividade docente para neles interferir, transformando-os.

É importante ressaltar que a prática, apesar de se tratar de um termo bem abrangente e significativo, necessita estar intimamente ligada a ação dotada de sentido do seu agir, na qual o sujeito possui função imprescindível como agente numa estrutura social. De acordo com Sacristán (1999, p. 28):

A prática é entendida como a atividade dirigida a fins conscientes, como ação transformadora de uma realidade; como atividade social historicamente condicionada, dirigida à transformação do mundo; como a razão que fundamenta nossos conhecimentos. A prática pedagógica, entendida como uma práxis envolve a dialética entre o conhecimento e a ação com o objetivo de conseguir um fim, buscando uma transformação cuja capacidade de mudar o mundo reside na possibilidade de transformar os outros.

Desse modo, o professor, como sujeito do contexto educativo, que se apropria de ações de forma intencional, é formado em concomitância com os objetivos postos pela sociedade, que demandam por práticas das quais possam apoderar-se. Dessa forma, a transformação da realidade se dá por meio das ações que os docentes realizam na educação, manifestando- se e transformando o que acontece à sua volta.

A prática pedagógica, assim, envolve em seu limiar a experiência histórica das ações e a consolidação de formas de desenvolver a atividade docente, pois, segundo Sacristán (1999, p. 74), "A prática é, então, sinal cultural de saber fazer composto de formas de saber como, ainda que ligado também a crenças, a motivos e a valores coletivos". 
A formação continuada, por esse ponto de vista, é percebida como um meio de articular antigos e novos conhecimentos às práticas dos professores, evidenciando a ênfase da teoria e, com isso, gerando mudanças e transformações, considerando os aspectos da formação em que se baseiam tais práticas, uma vez que estas são fundamentadas em construções individuais e coletivas que ocorrem durante o tempo e nas suas relações.

Em vista disso, o professor, em processo de formação, consegue estabelecer e redimensionar a relação que se tem entre a sua prática, o campo teórico e os aspectos que permeiam a construção do seu trabalho, como a escola, os alunos, as políticas educacionais etc. De acordo com Imbernón (2010, p. 43), "Refletir sobre a prática educacional, mediante a análise da realidade do ensino, da leitura pausada, da troca de experiências. Estruturas que tornem possível a compreensão, a interpretação e a intervenção sobre a prática"

$O$ ato em si faz com que o professor passe a refletir sobre a prática e as relações que acontecem a partir dela, percebendo seus viés e entrelaçamentos. A reflexão, quando praticada de forma correta, ganha novo significado no campo do trabalho docente, mesmo que tal conceito não seja unívoco e possua diferentes enfoques epistemológicos. De acordo com Pérez Gómez (1998, p. 372), a reflexão:

[...] é uma forma de praticar a crítica com o objetivo de provocar a emancipação das pessoas, quando descobrem que tanto o conhecimento quanto a prática educativa são construções sociais da realidade, que respondem a interesses políticos e econômicos contingentes a um espaço e a um tempo e que, portanto, podem mudar historicamente.

Assim, é possível dizer que o homem vive em aprendizagem permanente, porque se encontra em um processo de amadurecimento constante, independente de idade, sexo e situação sociopolítica, que nunca será completamente concluído. Pode-se entender a formação continuada de professores não só em seu sentido formal, mas também de uma forma mais ampla, que inclui a sua participação na sociedade como verdadeiro cidadão, as suas experiências de vida e a sua bagagem cultural. 


\section{CONSIDERAÇÕES FINAIS}

Considerando a importância da formação continuada na vida profissional do educador, este artigo buscou responder à questão norteadora que originou a pesquisa e que procura saber: Qual a importância da formação continuada para os professores? Dessa forma, pode-se dizer que o processo de formação continuada faz parte das necessidades de desenvolvimento e crescimento do próprio sujeito, uma vez que a cada nova possibilidade de confrontar seus conhecimentos prévios existe a possibilidade de nova aprendizagem, um olhar diferente ao fazer e uma nova possibilidade de o saber fazer.

A experiência só é encarada como formação continuada pelo próprio sujeito. Cada professor agrega à sua prática as experiências positivas e negativas que entendem como adequadas, de modo que o professor seja capaz de refletir sobre o que tem feito e como tem feito e, assim, buscar outras maneiras de ser e fazer. É nesse contexto que se inserem as relações intersubjetivas que o professor estabelece com colegas e alunos.

Quando se trata da formação continuada, todo o cuidado deve ser empregado no planejamento e avaliação, nada deve ser improvisado, de modo que se possa contemplar essa atividade como um uma forma de aprender algo novo, por meio da reflexão sobre conhecimentos já adquiridos e com a aplicação desses conhecimentos em sala de aula.

Nesse processo, há uma via de mão dupla, em que: de um lado, aprende-se por meio das experiências de vida; e do outro, tenta-se compreender como esse aprendizado repercute em cada um dos docentes.

A partir dos estudos realizados, é possível dizer que o desenvolvimento do ser nunca é estático. O mundo se reinventa, o conhecimento científico avança e a maneira do professor perceber essas mudanças estão atreladas ao elo do saber e do saber fazer, rompendo paradigmas e se adequando às novas possibilidades e necessidades, 
principalmente em relação a utilização de recursos que atendam às necessidades da sociedade atual.

Dessa forma, conclui-se a formação continuada é de extrema importância no processo de aprimoramento do profissional da educação, de modo que possam desenvolver novos conhecimentos e na articular a teoria com a prática, pois, desta forma, será possível uma ampliação do universo de conhecimento dos professores, dos alunos, e da sociedade.

\section{REFERÊNCIAS}

ANDRÉ, M. E. D. A. de. Estudo de caso em pesquisa e avaliação educacional. Brasília: Líber Livro Editora, 2005.

CONTRERAS, J. D. La autonomía del profesorado. Madrid: Morata, 1997.

FIORENTINI, D. Formação de professores de Matemática: explorando novos caminhos com outros olhares. Campinas: Mercado das Letras, 2003, p. 159-192.

FREIRE, P. Pedagogia da Autonomia. $7^{a}$ ed. São Paulo: Paz e Terra, 1997.

GARRIDO, E., PIMENTA, S.; MOURA, M. A pesquisa colaborativa na escola como abordagem facilitadora para o desenvolvimento da profissão do professor. Educação continuada. Campinas: Papirus, p. 89-112, 2000.

MARIN, A. J. Educação continuada: reflexões, alternativas. Campinas: Papirus, 2002.

HARGREAVES, A. Aprendendo a mudar: o ensino para além dos conteúdos e da padronização. Porto Alegre: Artmed, 2002.

IMBERNÓN, F. Formação Continuada de professores. Porto Alegre: Artmed, 2010.

LIBÂNEO, J. C. Reflexividade e formação de professores: outra oscilação do pensamento pedagógico brasileiro. São Paulo: Cortez, 2002, p. 53-79. 
DICIONÁRIO MICHAELIS. Significado de formação. 2021. Disponível em: https://michaelis.uol.com.br/busca? $r=0 \& f=0 \& t=0 \&$ palavra=casa. Acesso em: 30 nov. 2021.

NASCIMENTO, M. das G. A Formação Continuada dos professores: modelos, dimensões e problemática. Ciclo de Conferências da Constituinte Escolar. Caderno Temático, Belo Horizonte, n. 5, 2000.

NÓVOA, A. Os professores e a sua formação. Lisboa: Dom Quixote, 1992.

NÓVOA, A. Vidas de Professores. 2ª ed. Lisboa: Porto Editora, 1995.

PÉREZ GÓMEZ, A. O pensamento prático do professor: a formação do professor como profissional reflexivo. Os professores e a sua formação. Lisboa: Dom Quixote, 1998.

PIMENTA, S. G. Professor reflexivo: construindo uma crítica. In: PIMENTA, S. G.; GHEDIN, E. (Org). Professor reflexivo no Brasil: gênese e crítica de um conceito. São Paulo: Cortez, 2002.

RODRIGUES, Â.; ESTEVES, M. A análise de necessidades na formação de professores. Porto: Porto Editora, 1993.

SACRISTÁN, J. G. Poderes instáveis em educação. Porto Alegre: Artmed, 1999.

SAVIANI, D. Os saberes implicados na formação do educador. Formação do educador: dever do Estado, tarefa da Universidade. São Paulo: Unesp, p. 145-155, 1996.

SCHÖN, D. A. Formar professores como profissionais reflexivos. Os professores e sua formação. Lisboa: Dom Quixote, v. 2, p. 77-91, 1992.

Enviado: Setembro, 2021.

Aprovado: Dezembro, 2021. 